\title{
Fecal Indicator Bacteria and Antibiotic Resistance Genes in Storm Runoff from Dairy Manure and Compost-Amended Vegetable Plots
}

\author{
Kyle Jacobs, Lauren Wind, ${ }^{*}$ Leigh-Anne Krometis, W. Cully Hession, and Amy Pruden
}

\begin{abstract}
Given the presence of antibiotics and resistant bacteria in livestock manures, it is important to identify the key pathways by which land-applied manure-derived soil amendments potentially spread resistance. The goal of this field-scale study was to identify the effects of different types of soil amendments (raw manure from cows treated with cephapirin and pirlimycin, compost from antibiotic-treated or antibiotic-free cows, or chemical fertilizer only) and crop type (lettuce [Lactuca sativa L.] or radish [Raphanus sativus L.]) on the transport of two antibiotic resistance genes (ARGs; sul1 and ermB) via storm runoff from six naturally occurring storms. Concurrent quantification of sediment and fecal indicator bacteria (FIB; Escherichia coli and enterococci) in runoff permitted comparison to traditional agricultural water quality targets that may be driving factors of ARG presence. Storm characteristics (total rainfall volume, storm duration, etc.) significantly influenced FIB concentration (two-way ANOVA, $p<0.05$ ), although both effects from individual storm events (Kruskal-Wallis, $p<0.05$ ) and vegetative cover influenced sediment levels. Composted and raw manure-amended plots both yielded significantly higher sul 1 and ermB levels in runoff for early storms, at least 8 wk following initial planting, relative to fertilizer-only or unamended barren plots. There was no significant difference between sul1 or ermB levels in runoff from plots treated with compost derived from antibiotictreated versus antibiotic-free dairy cattle. Our findings indicate that agricultural fields receiving manure-derived amendments release higher quantities of these two "indicator" ARGs in runoff, particularly during the early stages of the growing season, and that composting did not reduce effects of ARG loading in runoff.
\end{abstract}

\section{Core Ideas}

- Compost and manure soil amendments elevated FIB and ARGs in storm runoff.

- Composting manure prior to soil amendment did not reduce ARGs in runoff.

- Antibiotic and antibiotic-free composts had similar quantities of ARGs and FIB.

- Vegetable type influenced sediment concentrations, but not FIB or ARGs, in runoff.

- Storm characteristics affected both FIB and ARG levels.
G LOBALLY, millions of infections in humans are reported annually that cannot be treated with a simple single-antibiotic regimen (WHO, 2015; CDC, 2016), which poses a serious public health threat (Auerbach et al., 2007; Chang et al., 2015; CDC, 2016). Livestock agriculture is frequently identified as a possible environmental source of increasing antibiotic resistance. More than 13 million $\mathrm{kg}$ of antibiotics, many of which are of critical importance for human health, were purchased annually by the agricultural industry for use as feed supplements to promote herd health and weight gain (Sura et al., 2015; FDA, 2017). The use of antibiotics in livestock agriculture is potentially critical in the environmental management of resistance, as manure and derived amendments are applied to more than 8.9 million ha (22 million ac) of land annually as a soil conditioner and fertilizer (USDA National Agricultural Statistics Service, 2014). Given that many antibiotics are not completely metabolized when they pass through animal digestive systems, antibiotics and/or resistant bacteria are often elevated in these manures (Ray et al., 2017). The US Veterinary Feed Directive, implemented in 2015, prohibits the use of antibiotics as feed supplements except under the direction of a veterinarian (Davis et al., 2006; Chang et al., 2015; FDA, 2015b; Sura et al., 2015). This will likely reduce but not eliminate antibiotic levels in manure as antibiotic use will still remain an important aspect of maintaining animal health and welfare. Given that antibiotics have been widely used in livestock production for over $50 \mathrm{yr}$, antibiotic resistant bacteria (ARB) and resistance gene (ARG) levels in enteric bacterial populations may take many years to attenuate (Looft et al., 2012).

Previous work indicates that antibiotics, ARB, and ARGs found within land-applied animal manure and derivatives can be transported from fields amended with raw, stockpiled, or treated manures to surface waters via runoff following storm events (Frank, 2005; Davis et al., 2006; Ribeiro et al., 2012; Joy et al., 2013; Sun et al., 2013; Fahrenfeld et al., 2014; Sura et al., 2015). With the possibility of antibiotic resistance residuals contaminating agricultural systems (Zhang et al., 2014), recommendations

\footnotetext{
K. Jacobs, L. Wind, L.A. Krometis, W.C. Hession, Dep. of Biological Systems Engineering, Virginia Tech, Blacksburg, VA, 24060; A. Pruden, Dep. of Civil \& Environmental Engineering, Virginia Tech, Blacksburg, VA, 24060. Mention of trade names or commercial products in this article is solely for the purpose of providing specific information and does not imply recommendation or endorsement by USDA-NIFA. Assigned to Associate Editor Tim Johnson.
}

J. Environ. Qual. 48:1038-1046 (2019)

doi:10.2134/jeq2018.12.0441

Supplemental material is available online for this article.

Received 7 Jan. 2019.

Accepted 2 May 2019.

*Corresponding author (wlauren@vt.edu).

Abbreviations: ARB, antibiotic resistant bacteria; ARG, antibiotic resistance gene; FIB, fecal indicator bacteria; MLS, macrolide-lincosamide-streptogramin; MPN, most probable number; qPCR, quantitative polymerase chain reaction. 
are put into place to prevent environmental dissemination. The recent US Food and Drug Administration (FDA) Food Safety and Modernization Act of 2015 recommends manure composting prior to land application to control potential crop contamination with fecal pathogens (FDA, 2015a). Composting is also currently recommended as a best management practice to reduce the quantity of fecal indicator bacteria (FIB) and enteric pathogens in manure before land application (Pruden et al., 2013; Sharma et al., 2009; Ray et al., 2017). The majority of bacteria in manure (including Escherichia coli) are assumed to be mesophiles that cannot survive the elevated temperatures $\left(>55^{\circ} \mathrm{C}\right)$ during the thermophilic phase of composting; but composting is not effective at eliminating all pathogens, and therefore, residual $A R B$ and ARGs may still be present. Given the potential for horizontal transfer of ARGs between species, there is concern that ARGs from native enteric bacteria that persist through the composting process could subsequently pass resistance to human pathogens (Bennett, 1999; Kazimierczak and Scott, 2007; Sykes, 2010; Haug et al., 2011; Finley et al., 2013; Chang et al., 2015).

The potential for composting to reduce loadings of antibiotics, ARB, and ARGs is therefore of significant recent interest (FDA, 2015a). Observations of significant reductions (50-70\%) in multiple antibiotics (chlortetracycline, sulfamethazine, tylosin, pirlimycin, cephapirin) in composted agricultural wastes (Ray et al., 2017) does suggest that a potential reduction in selection pressure that would be expected to reduce ARB and ARG levels. Wang et al. $(2012,2015)$ reported that composting can decrease tetracycline and erythromycin resistant bacteria and their respective genes in manure by up to seven logs following small-scale composting at $55^{\circ} \mathrm{C}$. However, studies documenting the fate of antibiotics and ARGs during composting of manure emphasized that composting does not generally eliminate antibiotics or ARGs, and under some conditions, certain ARGs may increase (Storteboom et al., 2007; Sharma et al., 2009; Wang et al., 2012; Ray et al., 2017).

Manure-derived amendments can elevate, at least temporarily, various antibiotic resistance markers in soils (Yang and Carlson, 2003), which can be transported along with eroded sediment and FIB to local receiving waters (USEPA, 2016). Chen and Xia (2017) determined that engineered antibiotic resistance plasmids could readily be adsorbed to soil particles, suggesting that subsequent rainfall events could potentially increase the transport of ARGs via runoff as topsoil erodes. A simulated rainfall study by Joy et al. (2013) reported that absolute abundances of the ARGs tetQ and ermB were an order of magnitude greater in surface runoff from manure-amended plots $\left(8.5 \times 10^{2}\right.$ and $5.9 \times 10^{1}$ copy $\mathrm{mL}^{-1}$ runoff, respectively) than the control plots $\left(5.8 \times 10^{1}\right.$ and $5.0 \times 10^{\circ}$ copy $\mathrm{mL}^{-1}$ runoff $)$. It is important to recognize that previous efforts used laboratory-scale microcosm studies (Chen et al., 2018), simulated rainfall events (Joy et al., 2013), or 100-yr storm simulations (Sura et al., 2015) to generate runoff. To our knowledge, no previous controlled field study has directly compared the potential for ARG transport via runoff from manure versus compost-amended plots from natural rainfall.

The purpose of this study was to compare the release of ARGs, FIBs, and sediment from field-scale plots amended with differing raw manure or manure-derived composts from antibiotic-treated (i.e., pirlimycin and cephapirin) or nontreated dairy cows into runoff from naturally occurring storm events during the growing season. These findings will aid in evaluating the relative benefits (composting, antibiotic use regimens, etc.) of different comprehensive on-farm strategies for reducing the environmental spread of antibiotic resistance.

\section{Materials and Methods}

\section{Site Description}

A total of 27 study plots were installed at the Virginia Tech Urban Horticulture Center in Blacksburg, VA, on land that was previously fallow for at least a decade. Southwest Virginia has a humid continental climate that experiences about $104 \mathrm{~cm}$ precipitation annually and has a growing season from March to August. The 27 plots represented an unbalanced block design constructed to compare the effects of crop type and soil amendment type on sediment, FIB, and ARG recovery in runoff. Further site details, including a concurrent effort exploring the impacts of soil amendment on soil levels of culturable resistant coliform levels, are available in Wind et al. (2018). In brief, the targeted soil amendments and vegetables were (i) no amendments on barren soils (control; $n=3$ plots), (ii) inorganic chemical fertilizer-amended soils that grew lettuce (Lactuca sativa L.; $n$ $=3$ ) and radish (Raphanus sativus L.; $n=3$ ), (iii) soils that grew lettuce $(n=3)$ and radish $(n=3)$ and were amended with compost from dairy cows that received no antibiotics, (iv) soils that grew lettuce $(n=3)$ and radish $(n=3)$ and were amended with compost from dairy cows administered antibiotics; and (v) soils that grew lettuce $(n=3)$ and radish $(n=3)$ and were amended with raw manure from dairy cows that received antibiotics.

The primary soil on site was a fine-loamy, mixed, semiactive, mesic Haplic Glossudalfs, which is associated with low infiltration rates and high runoff potential. Soil was treated with glyphosate during summer 2015 before tillage to clear vegetation for a spring 2016 planting. Per standard farming practices, $3.4 \mathrm{t} \mathrm{ha}^{-1}$ of hydrolyzed lime was applied onto the soil without tilling to increase the $\mathrm{pH}$ from 5.5 to the recommended target level of $\mathrm{pH} 6.5$ for lettuce and radish crop production 6 mo before manure application (Virginia Cooperative Extension, 2015). Manure and compost amendments were measured out at the experimental site using a field scale and incorporated into the top $5 \mathrm{~cm}$ of the soil using a rake (each amendment had a separate rake to decrease potential contamination between treatments) at a rate of $6.72 \mathrm{Mg} \mathrm{ha}^{-1}$ per recommendation from a Virginia Agricultural Research and Extension Area Specialist (Allen Straw, personal communication, 2015) 4 wk before vegetable planting. Following Virginia Cooperative Extension (2015) guidelines, inorganic fertilizer (N-P-K; Southern States, Richmond, VA) was added to the fertilizer-only plots at rates recommended for optimal growth for lettuce (125100-100) and radish (50-50-50). Inorganic fertilizer was also added to manure and compost plots at rates of 100-100-75 and 50-50-20 (N-P-K) for lettuce and radish growth, respectively, due to insufficient nutrients to maximize yield in the raw manure and compost. All N-P-K additions were measured by weight, and the pellets were spread across each plot using a fertilizer spreader and incorporated into the top $5 \mathrm{~cm}$ of the soils using the amendment-specific rake. 


\section{Dairy Manure and Compost Production}

Manure was collected from lactating dairy cows raised for milk production with or without antibiotic administration (Ray et al., 2017). Cows that received antibiotics were given pirlimycin (a lincosamide class drug) via two intramammary doses of 50 mg each at peak lactation, which is a standard therapeutic level to treat mastitis, or cephapirin (a first-generation cephalosporin) via a single intramammary dose of $300 \mathrm{mg}$ at the end of lactation, in keeping with standard prophylactic treatment. Feces and urine from both cohorts of cows receiving antibiotics were mixed together and stored for $57 \mathrm{~d}$ before field application, and portions of manure from antibiotic-treated and untreated cows was separately composted according to Food Safety and Modernization Act recommendations (FDA, 2015a) as described by Ray et al. (2017). In brief, manure was mixed in various ratios with alfalfa (Medicago sativa L.) hay (4:1) and sawdust (4:3) to achieve an end C-to-N ratio of 25 to $30 \%$ and moisture content of 55 to $65 \%$. Compost piles, aerated with air pumps, reached a temperature of $>55^{\circ} \mathrm{C}$ on the second day of composting and maintained at this temperature for more than $5 \mathrm{~d}$.

\section{Plot Configuration and Runoff Sampling}

Each of the 3-m by 3-m plots was enclosed on three sides by 16-gauge galvanized steel plot borders inserted approximately 20 $\mathrm{cm}$ down to the clay horizon of the soil. The fourth downslope side was bordered by a gutter to collect runoff and sediment during natural storms. Plots were separated by at least $2 \mathrm{~m}$ on all sides to minimize potential aerial cross-contamination between soil amendments.

Runoff samples were collected using one pre-sterilized 11-L ( $\sim 3$ gal) bucket attached via a food-grade hose to the downslope side of the gutter collection system, resulting in one surface water runoff collection bucket per plot (Supplemental Fig. S1). Each bucket was sterilized with a $10 \%$ bleach solution immediately before each storm collection, followed by a thorough rinsing with municipal tap water. We collected the "first flush" (i.e., the first 11-L of surface runoff that collected into the sterilized bucket) for each sample, and subsequently all the downstream bacterial and molecular analyses were done using an aliquot of the first flush. Storms were collected based on forecasted rainfall depths and feasibility of preparation (i.e., not all storms were collected during the growing season). A storm was defined as sufficient rainfall to produce at least $11 \mathrm{~L}$ of runoff per plot. In total, runoff was collected during six naturally occurring storm events: four storms during the growing season, one storm post-harvest, and one storm post-harvest following the plot treatment with glyphosate per common practice the following autumn (Table 1). The collection of storm runoff post-glyphosate spray permitted observation of the effects of herbicide on FIB, ARG, and sediment runoff concentrations.

\section{Fecal Indicator Bacterial Quantification}

A 2-L subsample from each bucket was transported on ice to the laboratory for immediate analysis following each storm. Prior to subsampling, the runoff in each bucket was mixed to ensure a homogenous sample of sediment and microorganisms. The FIB were quantified in each runoff sample via IDEXX Colilert and Enterolert defined Substrate Technology. The IDEXX QuantiTray/2000 system quantifies FIB via a most probable number (MPN) approach (www.idexx.com). If the maximum detection limit (2419 MPN $100 \mathrm{~mL}^{-1}$ ) was reached, the sample was diluted appropriately and reanalyzed within $24 \mathrm{~h}$ of the original sample collection. Reruns were required for $\sim 12 \%$ of all enterococci data.

\section{DNA Extraction and qPCR}

At least $10 \mathrm{~mL}$ of runoff was concentrated via vacuum filtration to filter-capture DNA onto Isopore Membrane Filters $0.4 \mu \mathrm{m}$ HTTP poly-carbonate filters (MilliporeSigma). Filtration was completed within $72 \mathrm{~h}$ of sample collection. Larger volumes often proved prohibitively difficult to filter-capture due to high levels of suspended sediment that caused clogging.

Filters were stored in $1.5 \mathrm{~mL}$ cryotubes at $-80^{\circ} \mathrm{C}$ before DNA extraction and quantitative polymerase chain reaction (qPCR) analysis. DNA was extracted using the FastDNA SPIN Kit for Soil following manufacturer's instructions (MP Biomedicals, LLC). Inhibition was addressed using the OneStep PCR Inhibitor Removal Kit (Zymo Research).

Extracted DNA samples were analyzed using known published qPCR protocols for 16SrRNA (Suzuki et al., 2000), sul1 (Pei et al., 2006), and ermB (Chen et al., 2007). Gene copies were quantified via qPCR on a CFX96 Real Time System (BioRad). Dilutions varied depending on gene analyzed (16S, 1:100; sul1, 1:50; erm B, 1:1). Standard curves ranging from $10^{3}$ to $10^{10}$ gene copies $\mu \mathrm{L}^{-1}$ for $16 \mathrm{~S}$ rRNA, $10^{3}$ to $10^{6}$ gene copies $\mu \mathrm{L}^{-1}$ for sull, $10^{1}$ to $10^{3.5}$ gene copies $\mu \mathrm{L}^{-1}$ for $\operatorname{erm} B$, and a negative control were analyzed in triplicate on each 96-well plate. The limit of quantification was established as the lowest amplified standard from the curve for each associated 96-well plate, which ranged between $10^{1}$ and $10^{3}$. The minimum acceptable standard curve $R^{2}$ was 0.97 . To determine relative abundance, concentrations of

Table 1. Characteristics of the six natural storm events collected during the study.

\begin{tabular}{|c|c|c|c|c|c|c|}
\hline Storm date & Days after planting & Total rainfall depth & Storm duration & $\begin{array}{l}\text { Total theoretical } \\
\text { volume per plot } \dagger\end{array}$ & $\begin{array}{l}\text { Average first hour } \\
\text { intensity }\end{array}$ & $\begin{array}{l}\text { Percentage } \\
\text { collected } \neq\end{array}$ \\
\hline & $d$ & $\mathrm{~mm}$ & $\mathrm{~h}$ & $\mathrm{~L}$ & $\mathrm{~mm} \mathrm{~h}^{-1}$ & $\%$ \\
\hline 30 Apr. 2016 & 1 & 25.5 & 18.0 & 229 & 3.3 & 4.8 \\
\hline 10 May 2016 & 11 & 12.9 & 16.5 & 116 & 2.7 & 9.5 \\
\hline 20 May 2016 & 21 & 23.2 & 5.8 & 209 & 5.9 & 5.3 \\
\hline 4 June 2016 & 36 & 28.4 & 20.3 & 255 & 2.6 & 4.3 \\
\hline 27 July 2016 & 89 & 16.8 & 1.3 & 151 & 16.7 & 7.3 \\
\hline 19 Sept. 2016 & 143 & 15.1 & 24.3 & 136 & 9.5 & 8.1 \\
\hline
\end{tabular}

† Theoretical volume calculated by multiplying the area of the plot by the depth of rainfall.

$\neq \%$ of total runoff collected in first flush. 
ARGs in this controlled field study were normalized to the concentrations of $16 \mathrm{~S}$ rRNA, which are generally considered indicative of total prokaryotic numbers (Janda and Abbott, 2007).

\section{Sediment Quantification}

Sediment concentrations were quantified via Standard Method 2540D for total suspended solids (APHA, 1997). For sediment filtration, $100 \mathrm{~mL}$ was subsampled from the 2-L runoff aliquot, filtered through a 47 -mm-diameter $1.5-\mu \mathrm{m}$ pore size filter via vacuum filtration, and dried and weighed according to Standard Method 2540D (APHA, 1997).

\section{Storm Effect Criteria}

Storms varied substantially in intensity and duration (Table 1). Because storms occurred during different periods within the growing cycle, differences in sediment, FIB, or ARG levels in runoff could relate to a range of covariates, including temperature, existing soil moisture, ultraviolet exposure prior to rainfall, ground cover, and overall seasonality in addition to storm size. Because this was a controlled field study, with these constantly changing complex factors, it was not appropriate to individually analyze the impacts of any single factor on runoff concentrations. Instead, significant differences between storms were viewed as a "storm effect" that included both seasonal and stormsize variables.

\section{Statistical Analysis}

Data were analyzed in $\mathrm{R}$ version 3.3.2 (R Core Team, 2016). A two-way ANOVA evaluated the effects of FIB concentrations (enterococci and E. coli), first-flush sediment load, and gene concentrations (16S rRNA, sull, and ermB) across all storms. Normality/non-normality of the data was confirmed by observing the normal Q-Q plot of the residuals. If the residual $\mathrm{Q}-\mathrm{Q}$ plots were not normal, revisualization of the data via $\mathrm{Q}-\mathrm{Q}$ plots was used to ensure best fit of the data. The FIB and ARGs were normalized to a $\log 10$ scale, the $16 \mathrm{~S}$ rRNA data were normalized by taking the square root, and the sediment data were normalized to a natural $\log$ scale. A two-way ANOVA was used to observe the interaction between storm effect and treatment. A pairwise $t$ test was used as a post-hoc analysis following a significant two-way ANOVA, which separated storms or treatments into significantly different groups. Significance was set at $\alpha=0.05$.

The Kruskal-Wallis test was used to determine the effects of the treatments within individual storms (Hollander and Wolfe, 1973). This nonparametric one-way ANOVA was selected since the data within individual storms were not always normally distributed even post-transformations. The post-hoc Dunn's test was used following a significant Kruskal-Wallis test (R package FSA; Ogle, 2017).

\section{Results and Discussion}

\section{Runoff and Sediment}

Sediment concentrations recovered in the first flush of runoff ranged from 3.5 to $191 \mathrm{~g}$ over the six storm events sampled (Fig. 1). Both storm effect (two-way ANOVA; $p<0.0001$ ) and vegetable type (two-way ANOVA; $p=0.039$ ) had significant impacts on first-flush sediment in runoff across all storms. A post-hoc analysis indicated that Storms 1 and 2 led to the highest first-flush sediment release in runoff across all treatments, whereas Storm 3 yielded the lowest. Storms 4, 5, and 6 released significantly lower sediment concentrations than Storms 1 and 2.

As noted above, it is important to recognize that "storm effect" is not synonymous with storm size, as storm effect includes storm size, intensity, time relative to the growing season, and so on. The complexity of these many covariates is clear when visually reviewing the data for trends. For example, following the storm with the greatest first hour of rainfall intensity, Storm 5 yielded runoff with lower, but not significantly different mean total suspended solids concentrations than the runoff from Storm 4 (0.04 $\mathrm{g} \mathrm{mL}^{-1}$ and $0.10 \mathrm{~g} \mathrm{~mL}^{-1}$, respectively), although Storm 3 was the
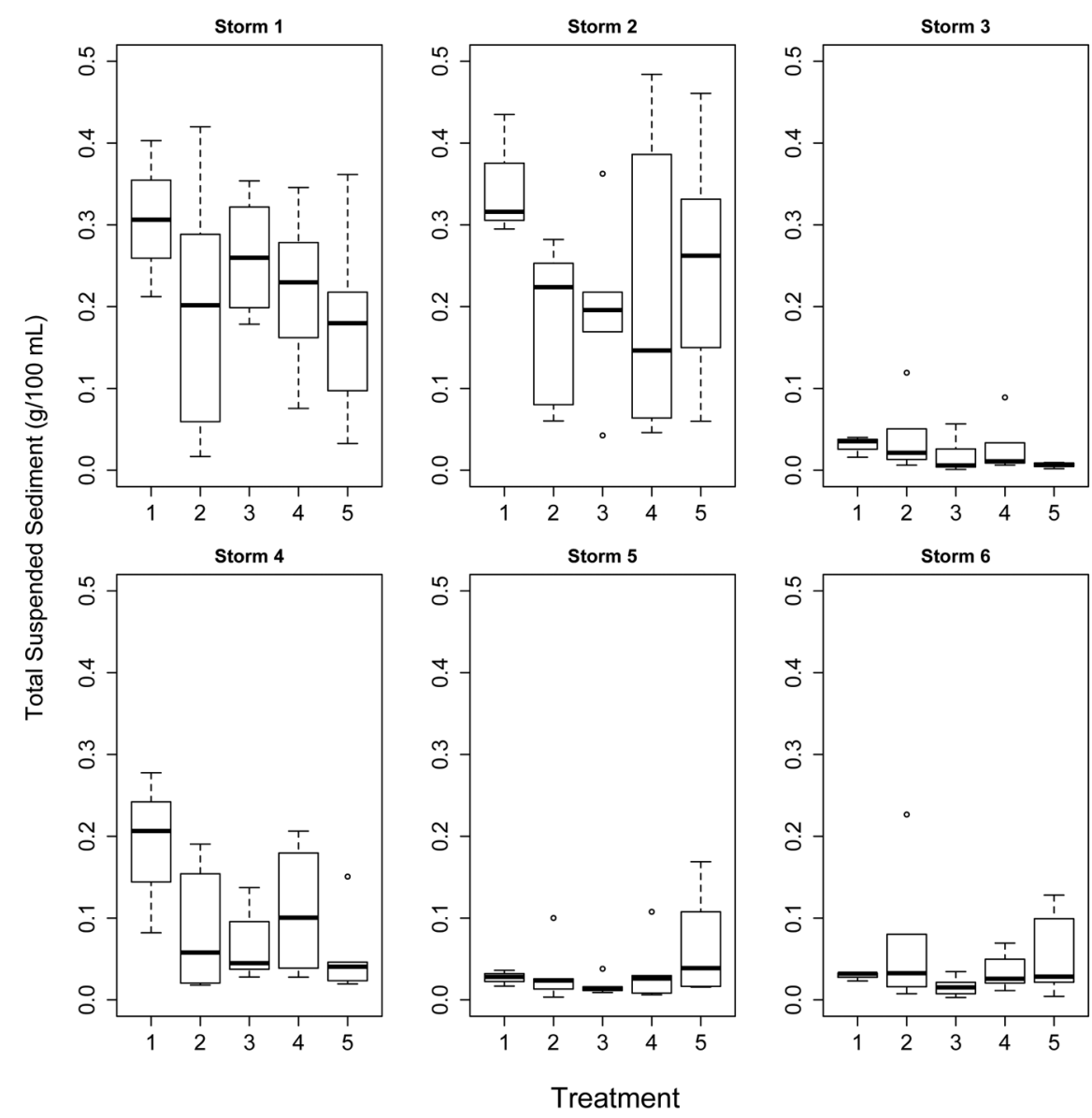

Fig. 1. Sediment concentrations (g sediment $100 \mathrm{~mL}^{-1}$ ) in runoff collected from each storm for combined lettuce and radish triplicate plots of each treatment: 1. control (barren, no amendment); 2 . chemical fertilizer; 3 . compost without antibiotics; 4 . compost with antibiotics; and 5. raw manure with antibiotics. Individual points indicating outliers $(n=162) . Y$-axis range maintained consistent to facilitate comparisons across storms. 
smallest in terms of first hour rainfall intensity (Fig. 1, Table 1). The first two storms yielded significantly greater first-flush sediment loads than later storms, whereas barren plots released more sediments than did nonbarren plots. Higher sediment yields associated with the early storms likely resulted from lack of vegetation cover-which is known to increase soil stability and decrease erosion-and movement of easily transported, loose sediments in the plots due to construction, tilling, and planting. Results of the Kruskal-Wallis tests indicated that within individual storms, there were no significant differences in sediment based on soil amendment or vegetable type (Kruskal-Wallis; $p$ > $0.05)$. This was unexpected, as it was anticipated that the barren control plots would yield more sediment in runoff than those planted with lettuce or radishes. Decreases in sediment in runoff in Storm 5 and Storm 6 (i.e., post-harvest) may be due to the overgrowth of weeds within plots.

\section{Fecal Indicator Bacteria Recovery}

Both $E$. coli and enterococci were detected at high levels in runoff, with maximum observations of $10^{6} \mathrm{MPN} 100 \mathrm{~mL}^{-1}$ for E. coli and $10^{7} \mathrm{MPN} 100 \mathrm{~mL}^{-1}$ for enterococci across all treatments and storms (Supplemental Fig. S2, Supplemental Fig. S3). These values are several orders of magnitude higher than USEPA (2012) recommended culturable $E$. coli levels in recreational freshwaters, which is a geometric mean of 126 colony forming units $100 \mathrm{~mL}^{-1}$. Substantial quantities of both indicators were even detected in runoff from plots that did not receive any manure-based amendments (i.e., control plots and plots treated with inorganic chemical fertilizer). For example, enterococci concentrations were as high as $1.4 \times 10^{7} \mathrm{MPN} 100 \mathrm{~mL}^{-1}$ in runoff from plots receiving only inorganic fertilizer. Concentrations of $E$. coli in runoff from control plots (no inorganic or manure amendment) were as high as $2.4 \times 10^{5} \mathrm{MPN} 100 \mathrm{~mL}^{-1}$.

Each storm resulted in significantly different concentrations of both types of FIB recovered in runoff samples (two-way ANOVA; $p<0.0001)$ when comparing them to the cohort of all six storms (Supplemental Table S1). The post-hoc analysis indicated that for $E$. coli, Storms 4 and 5 yielded significantly higher average concentrations in runoff than other storms. Enterococci data indicated that Storms 4, 5, and 6 released significantly higher average concentrations in the runoff than other storms. However, per individual storm, neither crop cover nor treatment type were significant for $E$. coli or enterococci concentrations (two-way ANOVA; $p>0.05$; Kruskal-Wallis; $p>0.05$ ), except for in Storm 1, where enterococci concentrations were significantly greater in runoff collected from plots amended with compost without antibiotics (Kruskal-Wallis; $p=0.036$ ). A pairwise $t$ test for $E$. coli concentrations indicated that Storms 2 and 3 released significantly lower concentrations of $E$. coli in runoff as compared to Storms 4 and 5. Storm 4 and Storm 5 yielded the highest average $E$. coli concentrations in runoff, while Storm 1 yielded the lowest average $E$. coli concentrations (Supplemental Table S1). Similarly, Storms 1, 2, and 3 released significantly less enterococci than the other storms, while Storm 5 resulted in the greatest release of enterococci in runoff (Supplemental Table S1). Post-hoc analysis indicated that Storms 1, 2, and 3 were all statistically similar in terms of enterococci levels in runoff, while Storms 4, 5, and 6 were each uniquely distinct.

\section{5 rRNA Gene Copy Numbers}

$16 S$ rRNA gene copy numbers were quantified as an indicator of "total bacterial" loads in the runoff. Mean gene copy numbers ranged from $10^{8}$ to $10^{19} 16 \mathrm{~S}$ rRNA copies $100 \mathrm{~mL}^{-1}$, with an upward trend over the course of the study period as Storm 1 had the lowest $\left(5.13 \times 10^{8} 16 \mathrm{~S}\right.$ rRNA copies $\left.100 \mathrm{~mL}^{-1}\right)$ and Storm 6 had the highest $\left(4.98 \times 10^{9} 16 \mathrm{~S} \mathrm{rRNA}\right.$ copies $100 \mathrm{~mL}^{-1}$; Supplemental Fig. S4). Individual storms had significantly different levels of $16 \mathrm{~S}$ rRNA genes; however, across all six storms there was no crop nor treatment effect on total numbers of bacterial abundance. Because the $16 \mathrm{~S}$ rRNA gene assay used universal primers, with the intention of measuring the full soil bacterial population, it is not unexpected that the trends are distinct from those specifically observed for FIB. In particular, the trend of increasing 16S rRNA gene copy numbers in runoff collected across the plots with time could be associated with elevated microbial growth rates as soil temperatures increased throughout the growing season. Over the course of six storms from late April to mid-September, the mean daily maximum temperatures between each storm significantly affected the mean 16S rRNA levels quantified in the runoff (Spearman's rank correlation; $p=$ $0.033)$.

\section{sul1}

The sul 1 gene encodes resistance to sulfonamides and was selected as a general culture-independent marker of antibiotic resistance. The sul1 gene is fairly widespread, correlating strongly with anthropogenic inputs in watersheds (Pruden et al., 2012), as sulfonamide antibiotics have been on the market longer than any other antibiotic. Furthermore, sul1 is often associated with class 1 integrons, which have similarly been identified as a highly suitable target for monitoring multi-antibiotic resistance and its potential for horizontal gene transfer (Gillings et al., 2014; Deng et al., 2015). There was no significant differences of storm or treatment effect on sul1 absolute abundance (Supplemental Fig. S5). sul1 was normalized to $16 \mathrm{~S}$ rRNA gene copy numbers (i.e., relative abundance) to account for minor variability in DNA extraction efficiency and as an indicator of the proportion of the bacterial community carrying this ARG (Fig. 2).

Over the course of the study, sul1 relative abundance ranged from $10^{-6}$ to $10^{-1}$ across all plots (Fig. 2). There was no overall significant soil amendment or storm effect on sul1 copies/16S rRNA gene copies in runoff (two-way ANOVA; $p>0.05$ ). However, within individual storms, soil amendment conditions appeared to be an important factor affecting runoff sul1 levels (Kruskal-Wallis; $p<0.05$; Fig. 2). During Storm 1, plots amended with raw manure containing antibiotics, compost with antibiotics, or compost without antibiotics yielded runoff with elevated sul1 copies/16S rRNA gene copies (Kruskal-Wallis; $p<0.05$ ). During Storm 2, runoff from the raw manure with antibiotics plots yielded significantly higher sul1 relative abundance. During Storm 3, sul1 relative abundance in runoff was still significantly higher in the manure- or compost-amended plots compared with the fertilizer control plots (Kruskal-Wallis; $p<0.05$ ), but it is important to note that relative abundance had decreased significantly compared with Storms 1 and 2. There was no significant effect of the various plot conditions on relative sul1 release in runoff for 
Storms 4 or 5. Interestingly, for Storm 6, the unamended barren control plots had the highest sul1 relative abundance in the associated runoff than any other treatments. This could potentially be related to the spraying of glyphosate between Storms 5 and 6, as herbicides have been noted by others to sometimes exert antibiotic resistance selection pressure (Kurenbach et al., 2018). Perhaps the glyphosate addition to the barren plots exerted more of a "shock" to the microbial community relative to that experienced by the more regularly disturbed amended and cultivated plots.

In general, sul1 relative abundance was higher in runoff from plots treated with either compost or manure at the beginning of the study, but not after harvest. Although sull remained detectable in runoff, the relative abundance of sul 1 genes decreased over time due to the increasing $16 \mathrm{~S}$ rRNA gene copy numbers. Decreases in the proportion of sul 1 copies carried by bacterial populations suggests decreasing selection pressure, poorer survival of sul1-carrying bacteria, and overall attenuation of this antibiotic resistance indicator with time. Interestingly, sul1 relative abundance in runoff from composted plots was not distinguishable from that of manured plots, indicating that composting did not act to reduce sul1 relative abundance, although it did substantially reduce antibiotic concentrations, as noted by Ray et al. (2017). Others have observed that composting can even elevate some ARGs, potentially due to the stress imposed by composting conditions ( $\mathrm{Su}$ et al., 2015; Storteboom et al., 2007). Notably, there was no difference in relative sul 1 between plots amended with compost derived from antibiotic-treated cows and antibiotic-free dairy cows. This suggests that the presence of residual antibiotics or metabolites was not a major driver of the observed patterns of sul1 occurrence. Udikovic-Kolic et al. (2014) also observed an increase in ARGs corresponding to drug classes that were not given to cattle when corresponding manure was amended to soil, which they attributed to stimulating native bacteria in the soil. A study of soil in the plots performed concurrently with the present study noted elevated sulfonamide-resistant fecal coliforms immediately following amendment application, but not thereafter (Wind et al., 2018).

\section{ermB}

The $\operatorname{erm} \mathrm{B}$ gene was selected as a target because it belongs to the macrolide-lincosamide-streptogramin (MLS) resistance category, corresponding to administration of pirlimycin (a lincosamide) to the dairy cattle that produced the manure for this study. Antibiotics belonging to the MLS class have a similar mode of action (protein synthesis inhibition) and corresponding
Storm 1

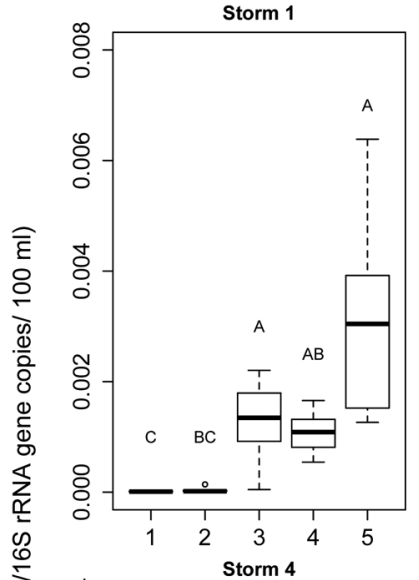

Fig. 2. sul1 gene copy numbers $100 \mathrm{~mL}^{-1}$ (normalized to 16SrRNA gene copies) in runoff collected antibiotics; and 5. raw manure. Individual points indicating outliers. $Y$-axis range is adjusted to zoom in on range of values measured for each individual storm. Significant differences between treatments are indicated by associated group letter.
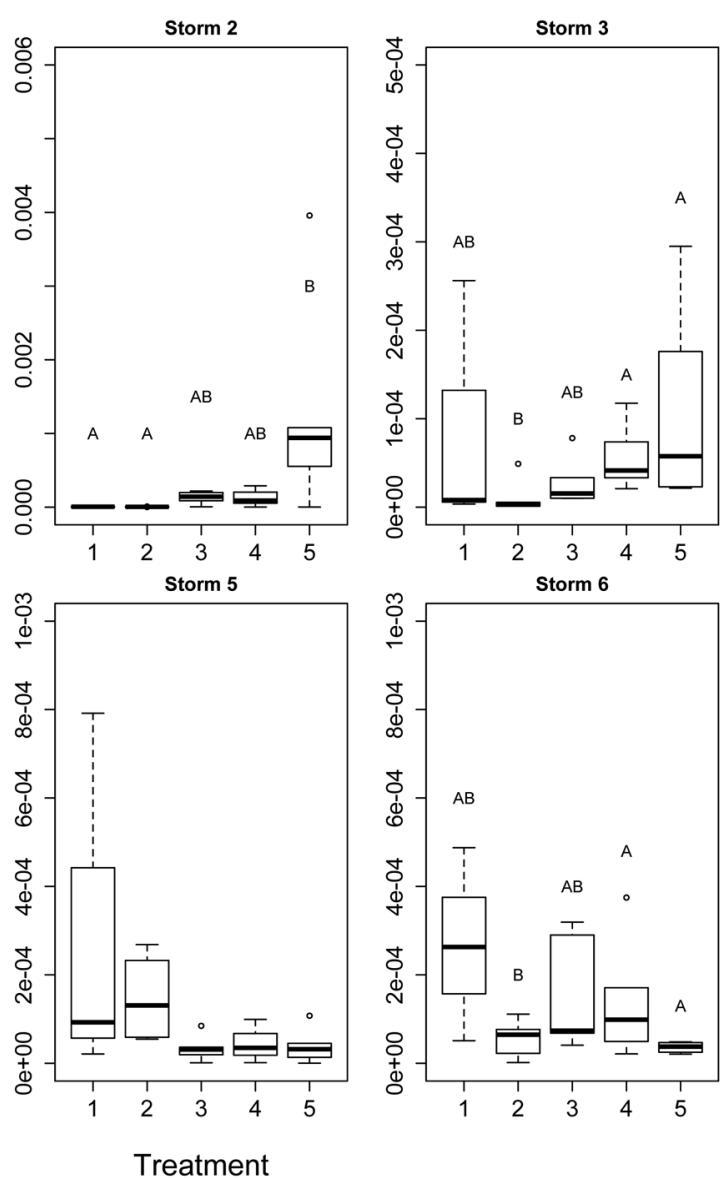

resistance mechanisms, with macrolides classified by the World Health Organization as being "critically important" and lincosamides as being "highly important" to human health (WHO, 2017). Although it was expected that plots amended with raw manure or compost derived from the cows administered antibiotics would yield higher quantities of erm B in runoff, this was not the case. There was no significant differences of storm or treatment effect on absolute erm B abundance (Supplemental Fig. S6). Further, the relative abundances of erm $\mathrm{B}$ in the runoff were much lower than those of sul $1\left(10^{-11}\right.$ to $10^{-4} \mathrm{ermB}$ copies/16S rRNA gene copies; Fig. 3).

During the study, erm B copies/16S rRNA copies ranged from $10^{-11}$ to $10^{-4}$ across all plots (Fig. 3). Similarly to sull, there was no significant soil amendment or storm effect on relative copies of $e r m \mathrm{~B}$ in runoff (two-way ANOVA; $p>0.05$ ). Comparing treatments within individual storms indicated that relative copies of erm B in runoff were distinct among plot treatments for Storms 1, 2, and 5 (Kruskal-Wallis; $p<0.05$ ). For Storm 1, the mean relative abundance of erm B copy numbers was higher in runoff from plots amended with raw manure $\left(1.36 \times 10^{-6} \mathrm{erm} B\right.$ copies/16S rRNA gene copies) and both compost types (compost without antibiotics, $5.23 \times 10^{-6}$; compost with antibiotics, $1.89 \times 10^{-6} \mathrm{erm} \mathrm{B}$ copies $/ 16 \mathrm{~S}$ rRNA gene copies) compared with the unamended barren control $\left(9.16 \times 10^{-8} \mathrm{erm} \mathrm{B}\right.$ copies $/ 16 \mathrm{~S}$ 

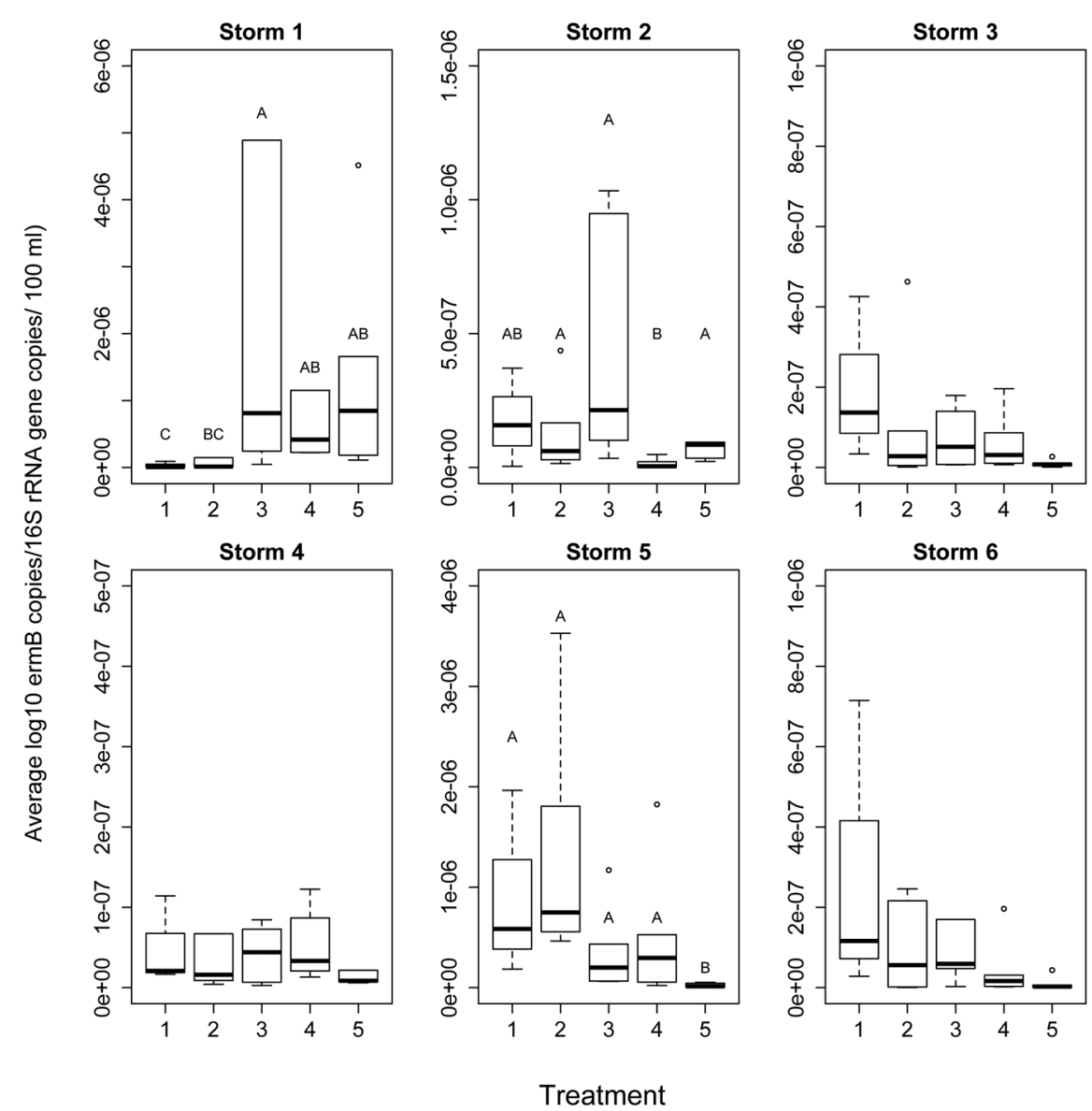

Treatment

Fig. 3. ermB gene copies $100 \mathrm{~mL}^{-1}$ (normalized to 16SrRNA gene copies) in runoff collected from each storm for combined lettuce and radish triplicate plots of each treatment: 1 . control (barren, no amendment); 2 . chemical fertilizer; 3 . compost without antibiotics; 4 . compost with antibiotics; and 5. raw manure. Individual points indicating outliers. $Y$-axis range is adjusted to zoom in on range of values measured for each individual storm. Significant differences between treatments are indicated by associated group letter.

rRNA gene copies) and inorganic fertilizer plots $\left(5.65 \times 10^{-8}\right.$ erm B copies/16S rRNA gene copies). During Storm 2, the compost without antibiotics $\left(4.24 \times 10^{-7}\right.$ erm B copies/16S rRNA gene copies) plots were associated with the highest erm $\mathrm{B}$ levels, and compost with antibiotics $\left(1.97 \times 10^{-8} \mathrm{erm} \mathrm{B}\right.$ copies/16S rRNA gene copies) plots were associated with the lowest erm $\mathrm{B}$ relative abundance in runoff. For Storm 5, only runoff from raw manure-amended plots $\left(2.08 \times 10^{-8} \mathrm{ermB}\right.$ copies/16S rRNA gene copies) was significantly lower than other soil treatments, with all other plot conditions being statistically equivalent.

\section{sul1 and ermB as Indicators of Manure-Related Sources of Resistance}

Two ARGs were targeted as potential indicators of manurerelated sources of antibiotic resistance in this study, using $\mathrm{qPCR}$ to obtain an integrated, culture-independent measure of their occurrence. Trends observed across plot conditions were largely similar: there was little to no measurable effect of compost versus raw manure or compost derived from antibiotic-administered versus antibiotic-free cattle on ARGs in runoff; and both genes indicated that manure-based amendments elevated ARG levels in runoff during early storms, but that effects attenuated with later storms. However, it is notable that sul 1 was a stronger indicator than erm $\mathrm{B}$ of the soil amendment conditions, even though an MLS antibiotic, and no sulfonamide, had been administered to the cattle. While both genes indicated low background levels, particularly in runoff collected from unamended barren and inorganic fertilizer-amended plots during Storm 1, relative abundance of sul 1 (1.33 $\times 10^{-5}$ and $4.31 \times 10^{-5}$ copies $100 \mathrm{~mL}^{-1}$, respectively) was $\sim 1,000$ times that of $\operatorname{erm} \mathrm{B}\left(9.16 \times 10^{-8}\right.$ and $5.65 \times 10^{-8}$ copies $100 \mathrm{~mL}^{-1}$, respectively).

sul 1 and $\operatorname{erm} \mathrm{B}$ copy numbers were elevated in the runoff from initial storms, consistent with these ARGs being enriched in the manure-derived soil amendments. Analysis of soil samples collected from the plots in a concurrent study indicated an initial decrease in erythromycin-resistant coliforms, followed by apparent regrowth later postharvest (Wind et al., 2018). However, there are numerous MLS ARGs, and it is not likely that there would be a 1:1 correspondence. Although there were significantly higher gene copy numbers of erm $\mathrm{B}$ in the runoff from compost plots in Storm 1 and 2, unamended barren control and inorganic fertilizer plots released higher relative gene copy numbers of erm B in Storms 3, 4, 5, and 6 than either compost or raw manure plots. This indicates that selective pressures may have been present that drove background erm $\mathrm{B}$ gene copy numbers native to the soil to grow during the experimental study or cross-contamination may have existed over the course of the experiments.

\section{Linking ARG Occurrence with Runoff Water Quality}

Exploring ARG occurrence concurrently with common measures of agricultural surface water runoff quality is useful in providing insight into mechanisms driving ARG transport, as well as in assessing the need for expanding water quality monitoring regimens. The two target ARGs did not behave similarly to culture-based FIB targets, suggesting that they were not the primary hosts of sul 1 and $\mathrm{erm} \mathrm{B}$ as observed in this study. Others have noted a general lack of correlation of ARGs with FIB in watershed monitoring programs. It is likely that FIB monitoring alone is not sufficient to predict ARG occurrence or movement in the environment.

While ARGs also did not significantly correlate with runoff sediment concentrations, this was probably driven largely by the fact that the highest sediment load occurred in the unamended barren plot, which also had low ARGs. However, it is worth noting that immediately following soil amendment and planting, fields are simultaneously most susceptible to sediment erosion and ARGs are initially elevated. This suggests this time should be a critical focus for best management practices to reduce losses due to overland flow following large storms. 
As there are currently no standard methods for measuring environmental sources of "antibiotic resistance," the selected target(s) should be suitable for the question of concern, such as resistance markers corresponding to administered or clinically important antibiotics. The current study provides support for targeting sul 1 as a sensitive and integrative culture-independent indicator of manure-related sources of antibiotic resistance. As is the case with the fecal indicator paradigm, antibiotic resistance indicators such as ARGs do not necessarily in and of themselves cause disease or represent immediate human health risk (Chang et al., 2015). It is important to recognize that there are natural background signatures of ARGs and that detection of a single ARG is not necessarily a human health concern (Wellington et al., 2013). However, identifying sensitive ARG targets indicative of potential for antibiotic resistance to spread could serve as a useful indicator for assessing effects of various on-farm management practices. Advancing human health risk models tailored to environmental sources of antibiotic resistance, as described in Ashbolt et al. (2013), can further aid in improved monitoring strategies designed to track and prevent human pathogen acquisition of new ARGs.

\section{Conclusions and Implications}

To our knowledge, the present study is the first to examine markers of antibiotic resistance in runoff from controlled field plots subject to natural storm events. Raw dairy manure and composts derived from antibiotic-treated and antibiotic-free cows were applied to vegetable field plots and compared with chemical fertilizer-only and unamended barren plot controls. No significant effect of any plot amendment or crop type (i.e., root or leafy) was observed with respect to runoff concentrations of $E$. coli, enterococci, or sediment across six subsequent natural storm events. One exception was that unamended barren control plots yielded greater quantities of sediment early in the growing season, likely because the lack of a cover crop rendered them more susceptible to erosion. Also, runoff sediment concentrations were highest over the first two storm events, shortly after manure-derived soil amendments were applied. Freshly tilled and amended plots could be most susceptible to transporting manure-derived antibiotic resistance elements with runoff, particularly if it is sediment associated.

Multiple methodological refinements would likely increase the ability of similar field studies to answer questions related to ARG persistence in agricultural runoff. The addition of on-site rain gauges adjacent to the plots would provide a more accurate volume of rainfall during storms. Also, collecting samples across the entire storm duration instead of the "first flush" would lead to further analyses about how FIB, sediment, and ARGs behave in runoff. This intrastorm sampling scheme would permit the calculation of FIB, total suspended solids, and ARG loadings within individual storms. In addition, continuous flow measurements of runoff from the plots would provide hydrographs to allow for determining relationships between FIB, sediment, or ARG loadings and flow across time during runoff events. Our findings confirm that agricultural fields applied with dairy manure-derived amendments are likely to release higher quantities of ARGs in runoff relative to those fields treated with inorganic fertilizer in runoff sampled closer to amendment application (Fig. 2 and 3). sul 1 and erm $\mathrm{B}$ exhibited slightly higher relative copy numbers in runoff samples collected from raw manure-amended soils during storms immediately after application and attenuating with time through the growing season. However, given that the chemical and physical properties of soil, background soil microorganisms, and antibiotic resistomes differ significantly among locations, further confirmatory studies in other distinct locales would be of value to ensure the relationship of manure-derived amendment application driving the ARG proliferation we observed in the early growing season. The findings of this study emphasize that appropriate runoff and sediment management could be a critical strategy for on-farm control of the spread of antibiotic resistance, potentially on par with judicious antibiotic use, appropriate manure treatment, and harvest wait times.

\section{Supplemental Material}

In depth description of runoff collection design; and additional figures and tables which quantify Enterococci, E. coli, and16S rRNA concentrations, and absolute abundances of sul 1 and $\operatorname{erm} \mathrm{B}$ in the runoff are provided in the supplemental material.

\section{Conflict of Interest}

The authors declare no conflict of interest with this work.

\section{Acknowledgments}

This study was supported by NIFA Competitive Grant no. 201405280/2015-68003-23050 from the USDA National Institute of Food and Agriculture. The authors appreciate the assistance of Laura Lehmann, Dumitru Branisteanu, and multiple undergraduate and graduate student volunteers in constructing the experimental plots at the field site. We particularly thank Austin Wozniak for his help in filtering runoff samples for ARG analyses.

\section{References}

APHA. 1997. SM 2540 D. In: Standard methods for the examination of water and wastewater. 21st ed. American Public Health Association, Washington, DC.

Ashbolt, N.J., A. Amézquita, T. Backhaus, P. Borriello., K.K. Brandt., P. Collignon, A. Coors, R. Finley, W.H. Gaze, T. Heberer, J.R. Lawrence, D.G.J. Larsson, S.A. McEwen, J.J. Ryan, J. Schönfeld, P. Silley, J.R. Snape, C. Van den Eede, and E. Topp. 2013. Human health risk assessment (HHRA) for environmental development and transfer of antibiotic resistance. Environ. Health Perspect. 121(9):993-1001. doi:10.1289/ehp.1206316

Auerbach, E.A., E.E. Seyfried, and K.D. McMahon. 2007. Tetracycline resistance genes in activated sludge wastewater treatment. Water Res. 41:1143-1151. doi:10.1016/j.watres.2006.11.045

Bennett, P.M. 1999. Integrons and gene cassettes: A genetic construction kit for bacteria. J. Antimicrob. Chemother. 43(1):1-4. doi:10.1093/jac/43.1.1

CDC. 2016. Antibiotic/antimicrobial resistance. Centers for Disease Control and Prevention, US Department of Health and Human Services. https:// www.cdc.gov/drugresistance/.

Chang, Q., W. Wang, G. Regev-Yochay, M. Lipsitch, and W.P. Hanage. 2015. Antibiotics in agriculture and the risk to human health: How worried should we be? Evol. Appl. 8:240-247. doi:10.1111/eva.12185

Chen, C., P. Ray, K.F. Knowlton, A. Pruden, and K. Xia. 2018. Effect of composting and soil type on dissipation of veterinary antibiotics in land-applied manures. Chemosphere 196:270-279. doi:10.1016/j. chemosphere.2017.12.161

Chen, C., and K. Xia. 2017. Fate of land applied emerging organic contaminants in waste materials. Curr. Pollut. Rep. 3:38-54. doi:10.1007/ s40726-017-0048-6

Chen, J., Z. Yu, F.C. Michel, T. Wittum, and M. Morrison. 2007. Development and application of real-time PCR assays for quantification of erm genes conferring resistance to macrolides-lincosamides-streptogramin B in livestock manure and manure management systems. Appl. Environ. Microbiol. 73(14):4407-4416. doi:10.1128/AEM.02799-06

Davis, J.G., C.C. Truman, S.C. Kim, II, and K. Carlson. 2006. Antibiotic transport via runoff and soil loss. J. Environ. Qual. 35(6):2250-2260. doi: $10.2134 /$ jeq2005.0348 
Deng, Y., X. Bao, L. Ji, L. Chen, J. Liu, J. Miao, D. Chen, H. Bian, Y. Li, and G. Yu. 2015. Resistance integrons: Class 1, 2, and 3 integrons. Ann. Clin. Microbiol. Antimicrob. 14(45). doi:10.1186/s12941-015-0100-6

Fahrenfeld, N., K. Knowlton, L. Krometis, W.C. Hession, K. Xia, E. Lipscomb, K. Libuit, B.L. Green, and A. Pruden. 2014. Effect of manure application on abundance of antibiotic resistance genes and their attenuation rates in soil: Field-scale mass balance approach. Environ. Sci. Technol. 48(5):2643-2650. doi:10.1021/es404988k

FDA. 2015a. Standards for the growing, harvesting, packing, and holding of produce for human consumption. Fed. Regist. 80(288):74353-74672. https://www.gpo.gov/fdsys/pkg/FR-2015-11-27/pdf/2015-28159.pdf.

FDA. 2015b. Veterinary feed directive. Fed. Regist. 80:31707-31735 https:// www.gpo.gov/fdsys/pkg/FR-2015-06-03/pdf/2015-13393.pdf.

FDA. 2017. 2016 Summary report on antimicrobials sold or distributed for use in food-producing animals. US Food \& Drug Administration. https:// www.fda.gov/downloads/forindustry/userfees/animaldruguserfeeactadufa/ucm588085.pdf.

Finley, R., P. Collignon, D. Larsson, S. Mcewen, X. Li, W. Gaze, R. Reid-Smith, M. Timinouni, D. Graham, and E. Topp. 2013. The scourge of antibiotic resistance: The important role of the environment. Clin. Infect. Dis. 57(5):704-710. doi:10.1093/cid/cit355

Frank, K. 2005. The effect of residential and agricultural runoff on the microbiology of a Hawaiian Ahupua'a. Water Environ. Res. 77(7):2988-2995. doi: $10.2175 / 106143005 X 73866$

Gillings, M., W. Gaze, A. Pruden, K. Smalla, J. Tiedje, and Y.-G. Zhu. 2014. Using the class 1 integron-integrase gene as a proxy for anthropogenic pollution. ISME J. 9(6):1269-1279. doi:10.1038/ismej.2014.226

Haug, M.C., S.A. Tanner, C. Lacroix, M.J.A. Stevens, and L. Meile. 2011. Monitoring horizontal antibiotic resistance gene transfer in a colonic fermentation model. FEMS Microbiol. Ecol. 78(2):210-219. doi:10.1111/j.1574-6941.2011.01149.x

Hollander, M., and D.A. Wolfe. 1973. Nonparametric statistical methods. John Wiley \& Sons, New York. p. 115-120.

Janda, J.M., and S.L. Abbott. 2007. 16SrRNA gene sequencing for bacterial identification in the diagnostic laboratory: Pluses, perils, and pitfalls. J. Clin. Microbiol. 45(9):2761-2764. doi:10.1128/JCM.01228-07

Joy, S.R., S.L. Bartelt-Hunt, D.D. Snow, J.E. Gilley, B.L. Woodbury, D.B. Parker, D.B. Marx, and X. Li. 2013. Fate and transport of antimicrobials and antimicrobial resistance genes in soil and runoff following land application of swine manure slurry. Environ. Sci. Technol. 47:12081-12088. doi:10.1021/es4026358

Kazimierczak, K.A., and K.P. Scott. 2007. Antibiotics and resistance genes: Influencing the microbial ecosystem in the gut. Adv. Appl. Microbiol. 62:269-292. doi:10.1016/S0065-2164(07)62009-7

Kurenbach, B., A.M. Hill, W. Godsoe, S. van Hamelsveld, and J.A. Heinemann. 2018. Agrichemicals and antibiotics in combination increase antibiotic resistance evolution. PeerJ 6:e5801. doi:10.7717/peerj.5801

Looft, T., T.A. Johnson, H.K. Allen, D.O. Bayles, D.P. Alt, R.D. Stedtfeld, W.J. Sul, T.M. Stedtfeld, B. Chai, J.R. Cole, S.A. Hashsham, J.M. Tiedje, and T.B. Stanton. 2012. In-feed antibiotic effects on the swine intestinal microbiome. Proc. Natl. Acad. Sci. USA 109:1691-1696. doi:10.1073/ pnas. 1120238109

Ogle, D.H. 2017. FSA: Fisheries stock analysis. R package version 0.8.13 https://github.com/droglenc/FSA

Pei, R., S. Kim, K.H. Carlson, and A. Pruden. 2006. Effect of river landscape on the sediment concentrations of antibiotics and corresponding antibiotic resistance genes (ARG). Water Res. 40:2427-2435. doi:10.1016/j. watres.2006.04.017

Pruden, A., M. Arabi, and H.N. Storteboom. 2012. Correlation between upstream human activities and riverine antibiotic resistance genes. Environ. Sci. Technol. 46(21):11541-11549. doi:10.1021/es302657r

Pruden, A., D.G.J. Larsson, A. Amezquita, P. Collignon, K.K. Brandt, D.W. Graham, J.M. Lazorchak, S. Suzuki, P. Silley, J.R. Snape, E. Topp, T. Zhang, and Y. Zhu. 2013. Management options for reducing the release of antibiotics and antibiotic resistance genes to the environment. Environ. Health Perspect. 121(8):878-885. doi:10.1289/ehp.1206446

R Core Team. 2016. R: A language and environment for statistical computing. $R$ Found. Stat. Comput., Vienna.

Ray, P., C. Chen, K.F. Knowlton, A. Pruden, and K. Xia. 2017. Fate and effect of antibiotics in beef and dairy manure during static and turned composting. J. Environ. Qual. 46(1):45-54. doi:10.2134/jeq2016.07.0269

Ribeiro, A.L., E. Laroche, G. Hanin, M. Fournier, L. Quillet, J. Dupont, and B. Pawlak. 2012. Antibiotic-resistant Escherichia coli in karstic systems: A biological indicator of the origin of fecal contamination? FEMS Microbiol. Ecol. 81:267-280. doi:10.1111/j.1574-6941.2012.01382.x
Sharma, R., F.J. Larney, J. Chen, L.J. Yanke, M. Morrison, E. Topp, T.A. McAllister, and Z. Yu. 2009. Selected antimicrobial resistance during composting of manure from cattle administered sub-therapeutic antimicrobials. J. Environ. Qual. 38:567-575. doi:10.2134/jeq2007.0638

Storteboom, H.N., S.C. Kim, K.C. Doesken, K.H. Carlson, J.G. Davis, and A. Pruden. 2007. Response of antibiotics and resistance genes to high-intensity and low-intensity manure management. J. Environ. Qual. 36:16951703. doi: $10.2134 /$ jeq2007.0006

Su, J., B. Wei, W. Ou-Yang, F. Huang, Y. Zhao, H. Xu, and Y. Zhu. 2015. Antibiotic resistome and its association with bacterial communities during sewage sludge composting. Environ. Sci. Technol. 49(12):7356-7363. doi:10.1021/acs.est.5b01012

Sun, P., D. Barmaz, M.L. Cabrera, S.G. Pavlostathis, and C. Huang. 2013. Detection and quantification of ionophore antibiotics in runoff, soil and poultry litter. J. Chromatogr. A 1312:10-17. doi:10.1016/j.chroma.2013.08.044

Sura, S., D. Degenhardt, A.J. Cessna, F.J. Larney, A.F. Olson, and T.A. McAllister. 2015. Transport of three veterinary antimicrobials from feedlot pens via simulated rainfall runoff. Sci. Total Environ. 521-522:191-199. doi:10.1016/j.scitotenv.2015.03.080

Suzuki, M.T., L.T. Taylor, and E.F. DeLong. 2000. Quantitative analysis of small-subunit rRNA genes in mixed microbial populations via 5'-nuclease assays. Appl. Environ. Microbiol. 66(11):4605-4614. doi:10.1128/ AEM.66.11.4605-4614.2000

Sykes, R. 2010. The 2009 Garrod lecture: The evolution of antimicrobial resistance-A Darwinian perspective. J. Antimicrob. Chemother. 65:18421852. doi: $10.1093 / \mathrm{jac} / \mathrm{dkq} 217$

Udikovic-Kolic, N., F. Wichmann, N.A. Broderick, and J. Handelsman. 2014. Bloom of resident antibiotic-resistant bacteria in soil following manure fertilization. Proc. Natl. Acad. Sci. USA 111(42):15202-15207. doi:10.1073/pnas.1409836111

USDA National Agricultural Statistics Service. 2014. 2012 census of agriculture United States: Summary and state data. USDA, Washington, DC. https:// www.agcensus.usda.gov/Publications/2012/Full_Report/Volume_1, Chapter_1_US/usv1.pdf (accessed 27 June 2017).

USEPA. 2012. Recreational water quality criteria. USEPA Office of Water 820F-12-058. https://www.epa.gov/sites/production/files/2015-10/documents/rwqc2012.pdf.

USEPA. 2016. National summary: Causes of impairment in assessed rivers and streams. USEPA. https://ofmpub.epa.gov/waters10/ attains_nation_cy.control\#causes.

Virginia Cooperative Extension. 2015. Commercial vegetable production recommendations: Virginia Publ. 456-420. Virginia Cooperative Extension, Blacksburg.

Wang, L., A. Gutek, S. Grewal, F.C. Michel, Jr., and Z. Yu. 2015. Changes in diversity of cultured bacteria resistant to erythromycin and tetracycline in swine manure during simulated composting and lagoon storage. Lett. Appl. Microbiol. 61(3):245-251. doi:10.1111/lam.12450

Wang, L., Y. Oda, S. Grewal, M. Morrison, F. Michel, and Z. Yu. 2012. Persistence of resistance to erythromycin and tetracycline in swine manure during simulated composting and lagoon treatments. Microb. Ecol. 63:32-40. doi: $10.1007 / \mathrm{s} 00248-011-9921-9$

Wellington, E., A. Boxall, P. Cross, E. Feil, W. Gaze, P. Hawkey, A. Johnson-Rollings, D. Jones, N. Lee, W. Otten, C. Thomas, and A. Williams. 2013. The role of the natural environment in the emergence of antibiotic resistance in Gram-negative bacteria. Lancet Infect. Dis. 13(2):155-165. doi:10.1016/ S1473-3099(12)70317-1

WHO. 2017. WHO list of critically important antimicrobials for human medicine (WHO CIA list). World Health Organization. https://www.who. int/foodsafety/publications/cia2017.pdf.

WHO. 2015. Antibiotic resistance. World Health Organization. http://www. who.int/mediacentre/factsheets/antibiotic-resistance/en/.

Wind, L., L.A. Krometis, W.C. Hession, C. Chen, P. Du, K. Jacobs, K. Xia, and A. Pruden. 2018. Fate of pirlimycin and antibiotic-resistant fecal coliforms in field plots amended with dairy manure or compost during vegetable cultivation. J. Environ. Qual. 47:436-444. doi:10.2134/jeq2017.12.0491

Yang, S., and K. Carlson. 2003. Evolution of antibiotic occurrence in a river through pristine urban and agricultural landscapes. Water Res. 37(19):4645-4656. doi:10.1016/S0043-1354(03)00399-3

Zhang, X., Y. Li, B. Liu, J. Wang, C. Feng, M. Gao, and L. Wang. 2014. Prevalence of veterinary antibiotics and antibiotic-resistant Escherichia coli in the surface water of a livestock production region in northern China. PLoS One 9(11):E111026. doi:10.1371/journal.pone.0111026 